\title{
Video Penyuluhan Hama Tanaman Dan Pengenalan Pestisida Produksi PT. Cba Mitra Petani Oleh PT. Anugerah Creative Media
}

\author{
Denny Andwiyan* ${ }^{1}$, Ria Wulandari ${ }^{2}$, Alam Putra Prasetyo ${ }^{3}$ \\ ${ }^{123}$ Program Studi Teknik Informatika, Fakultas Sains dan Teknologi, Universitas Raharja \\ Email: *1adwiyan@ raharja.info, ${ }^{2}$ wulandari@ raharja.info, ${ }^{3}$ alam@ @aharja.info
}

\begin{abstract}
Abstrak
Pada era globalisasi dunia, dibutuhkan strategi pemasaran yang baik, sehingga dapat menjangkau luasnya target pemasaran dari yang sebelumnya. PT. Anugerah Creative Media berlokasi di Tangerang Selatan ini bergerak dibidang creative. Perusahaan ini membutuhkan sebuah media implementasi guna membantu project kerjasama dengan klien PT. CBA Mitra yang membutuhkan sebuah video sebagai media penyuluhan hama tanaman bagi para petani. Permasalahannya adalah, saat ini PT. CBA Mitra masih memanfaatkan video penyuluhan yang sederhana. Observasi ini bertujuan untuk memberikan informasi dan meningkatkan pemasaran produksi PT. CBA Mitra. Manfaatnya yaitu PT. Anugerah Creative Media dapat memberikan promosi dan informasi yang terupdate mengenai PT. CBA Mitra. Penelitian ini melingkupi metode pengumpulan data, SWOT analysis, pengembangan media dan konsep produksi media $($ KPM), yang didalamnya terdapat pre production, production dan post production, serta meliputi software unggulan yaitu : Adobe Premiere Pro CC 2019, Adobe Audition CC 2019, Adobe After Effect CC 2019 dan Adobe Photoshop CC 2019. Melalui video penyuluhan ini, diharapkan petani atau masyarakat mengetahui informasi hama tanaman dari meningkatnya jumlah produk PT. CBA Mitra.
\end{abstract}

Kata Kunci - Penyuluhan, Hama Tanaman, Video

\begin{abstract}
In the era of global globalization, a good marketing strategy is needed, so that it can reach a wider range of marketing targets than before. PT. Anugerah Creative Media, located in South Tangerang, is engaged in the creative field. This company needs an implementation medium to help project collaboration with clients of PT. CBA Mitra who need a video as a medium for extension of plant pests for farmers. The problem is, currently PT. CBA Mitra still makes use of simple educational videos. This observation aims to provide information and improve the production marketing of PT. CBA Mitra. The benefit is that PT. Anugerah Creative Media can provide promotions and updated information about PT. CBA Mitra. This research covers data collection methods, SWOT analysis, media development and the concept of media production (KPM), which consists of pre production, production and post production, and includes superior software, namely: Adobe Premiere Pro CC 2019, Adobe Audition CC 2019, Adobe After Effect CC 2019 and Adobe Photoshop CC 2019. Through this counseling video, it is hoped that farmers or the public will find out information on plant pests from the increasing number of PT. CBA Mitra products.
\end{abstract}

Keywords - extension, plant pests, video

\section{PENDAHULUAN}

Penyuluhan merupakan ilmu sosial yang mempelajari sistem dan proses perubahan pada individu serta masyarakat agar terwujud perubahan yang lebih baik sesuai dengan yang diharapakan ${ }^{[1]}$. Video juga merupakan gabungan gambar-gambar mati yang dibaca berurutan dalam satu waktu dengan kecepatan tertentu. ${ }^{[2]}$

213 
PT. Anugerah Creative Media merupakan instansi creative yang melayani pembuatan karya audio visual atau video untuk menjadi sebuah pemasaran di era globalisasi dunia, PT. Anugerah Creative Media berlokasi di Ruko Thematik Blok P no. 5, Paramount, Gading Serpong, Curug Sangereng, Kelapa Dua Tangerang.

Permasalahan yang terdapat pada PT. Anugerah Creative Media yaitu, perusahaan saat ini membutuhkan sebuah media implementasi guna membantu project kerjasama dengan klien PT. CBA Mitra yang membutuhkan sebuah video sebagai media implementasi penyuluhan hama tanaman bagi para petani.

Untuk itu diperlukan adanya pengembangan video penyuluhan hama tanaman dan pestisida yang di produksi oleh PT. Anugerah Creative Media ini, dapat membantu PT. CBA Mitra dalam menginformasikan dan mempromosikan produk hama tanaman kepada petani.

Tujuan dari penggarapan video penyuluhan ialah memberikan update terbaru dengan rancangan video yang makin creative dan innovative, untuk menarik peminat dari petani atau masyarakat dan membantu bagian marketing dalam meningkatkan jumlah produk setiap tahunnya.

Melalui media penyuluhan dalam bentuk video ini, diharapkan para petani atau masyarakat dapat mengetahui jenis dan siklus pertumbuhan hama tanaman pada produk PT. CBA Mitra dan proses pencampuran produk hama tanaman.

\section{METODE PENELITIAN}

Metode yang digunakan dalam penelitian ini yaitu: (1) Metode Pengumpulan Data, metode ini memanfaatkan hasil dari Observasi yang telah dilakukan, Wawancara dan Studi Pustaka. (2) Video Penyuluhan Pada PT. Anugerah Creative Media ini memanfaatkan software, yaitu Adobe Premiere Pro 2019, Adobe Audition CC 2019, Adobe After Effect 2019 dan Adobe Photoshop 2019. (3) Konsep Produksi Media (KPM) melingkupi: Pre Production, Production dan Post Production.

\section{Literature Review}

Berikut adalah sejumlah observasi yang berhubungan dengan video penyuluhan ini yaitu:

1. Penelitian yang dilakukan oleh Mawan, dkk (2017) dengan judul "Pengembangan Video Penyuluhan Perilaku Hidup Bersih Dan Sehat (Phbs) Bermuatan Nilai Karakter Terhadap Peningkatan Pengetahuan Masyarakat Dalam Menanggulangi Penyakit Diare" Video penyuluhan adalah media audio-visual yang digunakan untuk memberikan pendidikan kepada masyarakat luas. ${ }^{[3]}$

2. Penelitian yang dilakukan oleh Acuña-Soto, et al (2018) dengan judul "Multiple criteria performance evaluation of YouTube mathematical educational videos by IS-TOPSIS", Video penyuluhan sangat diminati oleh para pendidik karena popularitasnya yang tinggi di internet, terutama di platform seperti YouTube yang telah menjadi salah satu sumber informasi yang paling banyak digunakan saat ini. ${ }^{[4]}$

3. Penelitian yang dilakukan oleh Safitri, dkk (2020) yang berjudul "Penggunaan Media Sosial Dalam Penyuluhan Pertanian Di Kecamatan Tiumang Kabupaten Dharmasraya" Penyuluhan merupakan suatu cara atau usaha pendidikan yang bersifat non formal untuk para petani dan keluarganya di pedesaan. ${ }^{[5]}$

4. Penelitian yang dilakukan oleh Putri dan Reza Safitri (2018) dengan judul "Peran Penyuluh Pertanian Terhadap Penerapan Teknologi Tanam Jajar Legowo 2:1 (Kasus Kelompok Tani Gotong Royong 2 Di Desa Klaseman, Kabupaten Probolinggo)" tujuan dari penelitian ini adalah untuk memotivasi para petani dengan kemampuan yang lebih baik dalam bertani dan mampu mengambil keputusan sendiri berlandaskan kualitas dan kuantitas yang lebih baik. ${ }^{[6]}$ 
5. Penelitian yang dilakukan oleh Salaki dan Jantje Pelealun (2019) yang berjudul "Pengendalian Hama Tanaman Padi Berbasis Ramah Lingkungan" tujuan dari penelitian ini adalah untuk menghasilkan pestisida nabati ramah lingkunganyang berasal dari tanaman obat dan aromatik yang mengandung minyak atsiri yang mendukung sistem pertanian yang berkelanjutan solusi yang dilakukan dalam kegiatan ini ialah bagaimana memberikan pengetahuan, ketrampilan dan pengalaman dengan cara penyuluhan, pelatihan dan demonstrasi plot. $^{[7]}$

\section{HASIL DAN PEMBAHASAN}

\subsection{Preproduction}

Pre production adalah tahapan awal untuk meyiapkan suatu video yang didalamnya terdapat konsep atau ide gagasan, rangkaian sinopsis, narasi, pembuatan storyboard, script writing, rundown, menetapkan crew yang akan berpartisipasi saat proses produksi, lalu menyusun time schedule, menentukan budget/anggaran dan mempersiapkan kelengkapan yang akan digunakan :

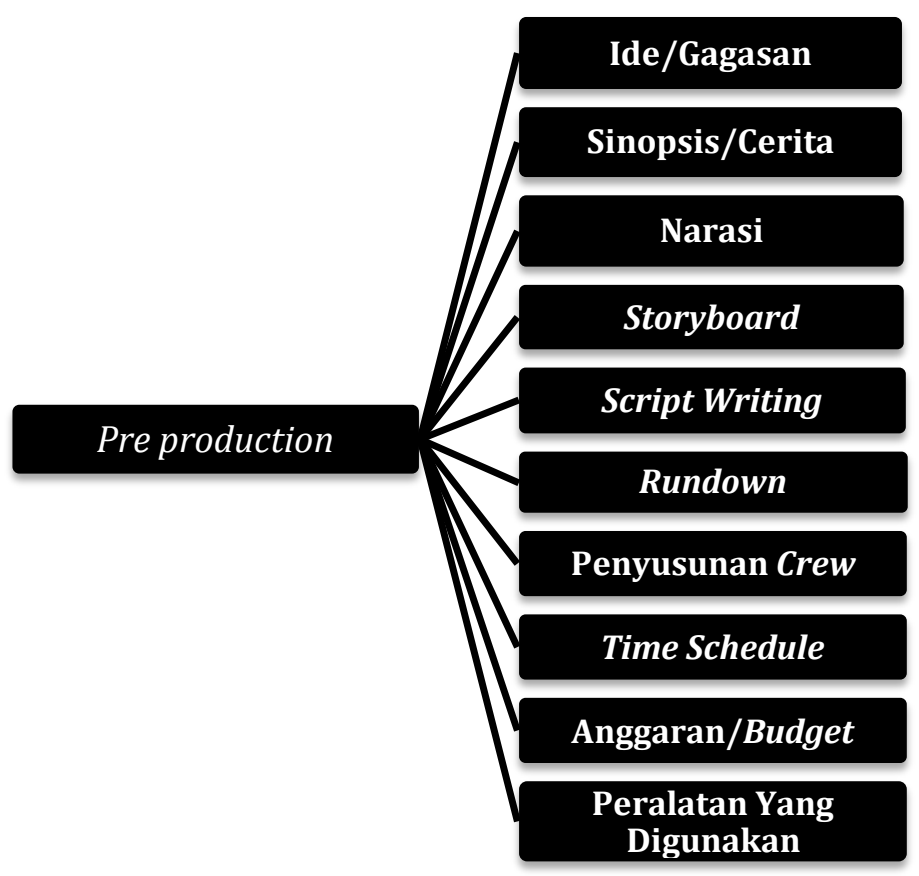

1. Ide/Gagasan

Gambar 1. Pre production

Sebuah rancangan awal proses Preproduction dari pengembangan media audio visual adalah menentukan Ide atau Gagasan. Suatu Ide atau Gagasan bisa berkembang melalui penelitian dan observasi pendataan dari permasalahan yang terjadi.

2. Sinopsis atau Cerita

Sinopsis ialah landasan inti dari suatu cerita yang disimpulkan secara singkat. Tahap awal dari proses ini adalah membentuk ide cerita yang mampu mengidentifikasikan permasalahan dari awal hingga akhir. Sinopsis pengembangan video penyuluhan hama tanaman PT. CBA Mitra Banten yang oleh PT. Anugerah Creative Media adalah sebagai berikut :

"Menampilkan video lahan tanaman. Lalu menampilkan footage tanaman dan logo PT. CBA Mitra. Kemudian menampilkan footage lahan tanaman. Selanjutnya menampilkan text hama 
yang sering menyerang tanaman hias dan bibit buah. Menampilkan lower third Tiodor dan TopGrow. Lalu menampilkan video penyemprotan tanaman hias. Kemudian menampilkan video penyuluhan terhadap petani atau masyarakat. Selanjutnya menampilkan video nomor telephone, marketplace dan logo PT. CBA Mitra."

\section{Narasi}

Narasi adalah cerita yang merupakan sebuah rangkaian peristiwa secara kronologis, baik berupa fakta, maupun fiksi. Berikut adalah narasi video penyuluhan hama tanaman PT. CBA Mitra :

"Banyak orang yang menyukai tanaman hias / tanaman hias memiliki penggermar setia yang jumlahnya tak sedikit // Selain sebagai pelengkap dekorasi rumah atau taman / bagi pedagang tanaman hias dapat menjadi peluang bisnis yang menjanjikan / tanaman hias tak hanya menjadi menyalur hobi saja / namun menjadi komunitas dengan nilai ekonomi yang cukup tinggi // Oleh karena itu tanaman hias harus dijadikan dengan benar / termaksud merawatmya agar terhindar dari berbagai hama dan penyakit tanaman / juga tanaman tumbuh lebih subur / terlihat menarik hingga meningkatkan nilai jual // Tanaman hias pun tak luput dari serangan hama bila tak ditanggulangi dengan baik // Hama Thrips / serangan terjadi didaun / terutama daun muda / daun sebagai organ utama tanaman menjadi rusak sehingga proses pertumbuhan dan perkembangan menjadi terhenti / kerusakan serangan hama ini dapat menurunkan kualitas 30\% hingga 60\% // Ulat Grayak / gejala serangannya / larva yang masih muda atau kecil / merusak daun dengan meninggalkan sisa-sisa epidermis bagian atas tranparan dan hanya nyisakan tulang-tulang daun saja / bahkan dikasus lain larva instar lanjut dapat merusak daun secara keseluruhan beserta buahnya // Belalang / seranganya dengan memakan daun-daun tanaman / sehingga mengurangi luas permukaan daun dan mengganggu fungsi fisiologis dari tanaman yang diserang // Untuk menanggulangi hama tersebut dapat mengunakan // Tiodor / Tiodor berbahan aktif imidakloprid 30wp / sebagai insektisida racun kontak dan lambung berbentuk tepung yang dapat diduspensikan dengan air / untuk mengendalikan hama warna coklat / Thrips / Apis / dan Ulat Grayak / takaran 1,5gr per liter air // TopGrow / TopGrow merupakan pupuk cair dengan kandungan unsur nitrogen 6\% / pospak 4\% dan kalium 3\% / berbentuk cairan berwarna hijau jernih / berfungsi untuk membantu mengoptimalkan pertumbuhan tanaman secara keseluruhan / baik akar / batang / daun / juga memaksimalkan bunga / takaran $14 \mathrm{ml}$ per liter atau $60 \mathrm{ml}$ per tengki / diumur 20 hari setelah tanam / dan disarankan semprot kembali setelah umur 10 sampai 40 hari setelah tanam //"

\section{Storyboard}

Storyboard merupakan ide cerita yang diterapkan melalui ilustrasi sketsa dan disempurnakan dengan petunjuk pengambilan gambar untuk terbentuknya sebuah rancangan shooting.

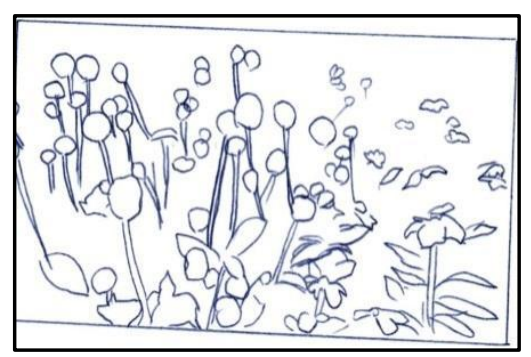

Gambar 2. Scene 1/Video Opening

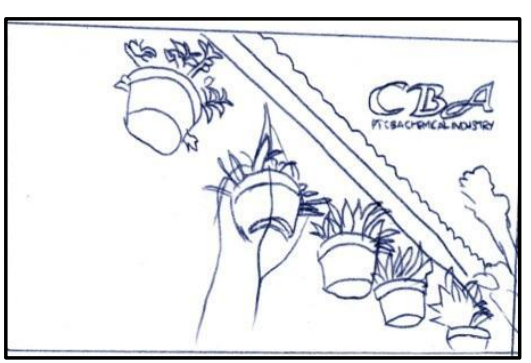

Gambar 3. Scene 2/Day/ Low Shot/Footage tanaman dan logo PT. CBA Mitra 


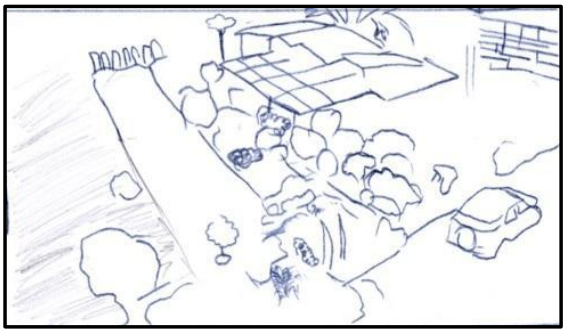

Gambar 4. Scene 3/Day/Long Shot/ footage lahan tanaman bunga

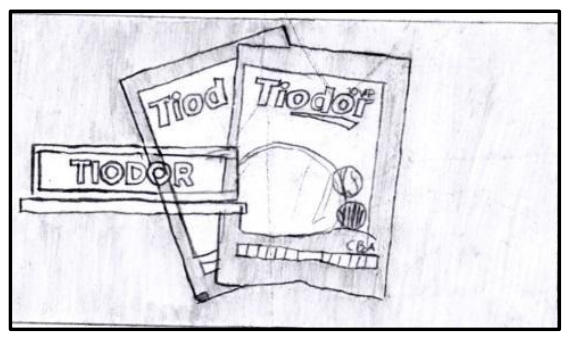

Gambar 6. Scene 5/Day/High Shot/Lower third Tiodor

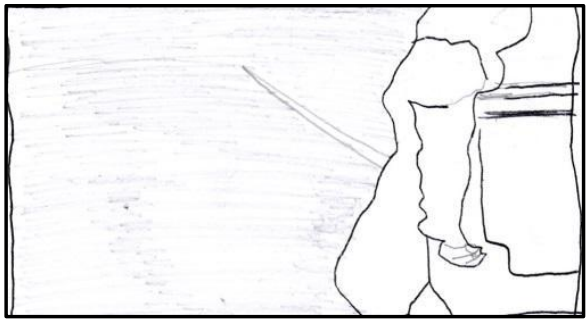

Gambar 8. Scene 7/day/Medium Shot/Video penyemprotan tanaman hias

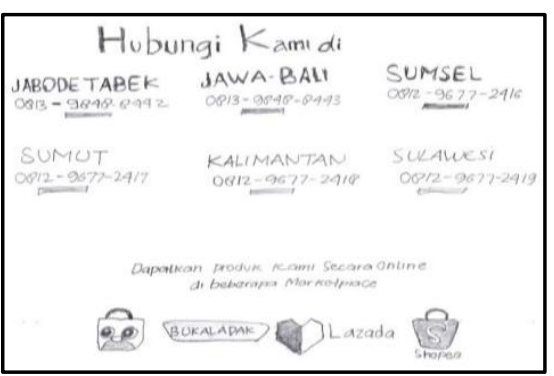

Gambar 10. Scene 9/Video nomor telephone,marketplace

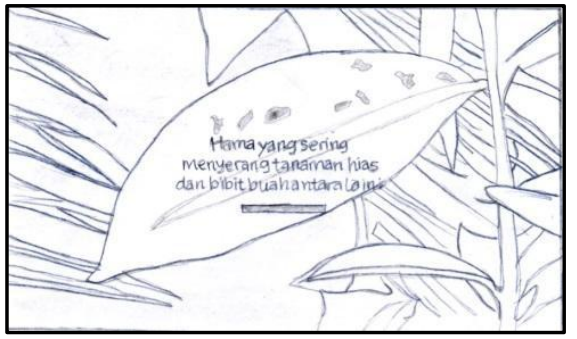

Gambar 5. Scene 4/Medium Shot/Text hama yang sering menyerang tanaman hias dan bibit buah

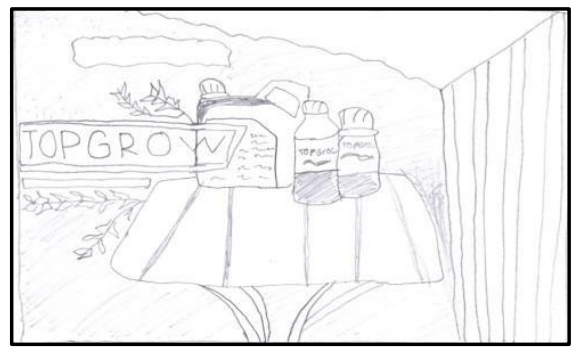

Gambar 7. Scene 6/Day/Long Shot/Lower third TopGrow

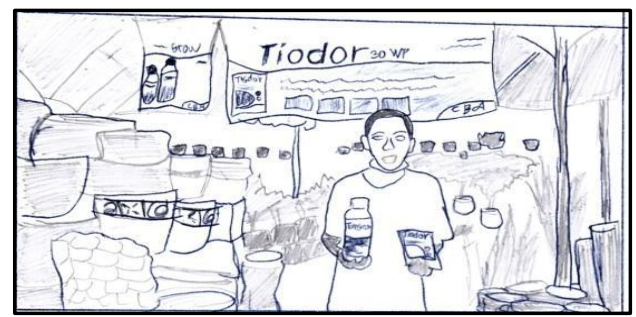

Gambar 9. Scene 8/Day/Medium

Shot/Video penyuluhan terhdap petani atau masyarakat

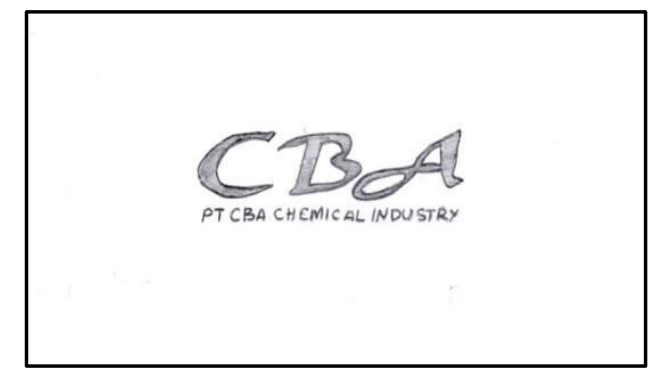

Gambar 11. Scene 10/Logo PT. CBA Mitra

5. Script Writing

Tabel 1. Script Writing

\begin{tabular}{|c|c|c|}
\hline No. & Visual & Audio \\
\hline 1. & Menayangkan video opening & Music \\
\hline
\end{tabular}


Print ISSN: 2723-1992

Online ISSN: 2723-200X

\begin{tabular}{|c|c|c|}
\hline 2. & $\begin{array}{c}\text { Menayangkan footage tanaman dan logo PT. } \\
\text { CBA Mitra }\end{array}$ & $\begin{array}{c}\text { Banyak orang yang menyukai } \\
\text { tanaman hias }\end{array}$ \\
\hline 3. & Menayangkan footage lahan tanaman bunga & $\begin{array}{c}\text { tanaman hias memiliki } \\
\text { pengermar setia yang } \\
\text { jumlahnya }\end{array}$ \\
\hline 4. & $\begin{array}{c}\text { Menayangkan text hama yang sering } \\
\text { menyerang tanaman hias dan bibit buah }\end{array}$ & Music \\
\hline 5. & Menayangkan lower third Tiodor & Tiodor \\
\hline 6. & Menayangkan lower third TopGrow & TopGrow \\
\hline 7. & $\begin{array}{c}\text { Menayangkan video penyemprotan tanaman } \\
\text { hias }\end{array}$ & Music \\
\hline 8. & $\begin{array}{c}\text { Menayangkan video penyuluhan terhadap } \\
\text { petani atau masyarakat }\end{array}$ & Music \\
\hline 9. & $\begin{array}{c}\text { Menayangkan video nomor telephone, } \\
\text { marketplace }\end{array}$ & Music \\
\hline 10. & Menayangkan video logo PT. CBA Mitra & Music \\
\hline
\end{tabular}

6. Rundown

Tabel 2. Rundown

\begin{tabular}{|c|c|c|c|c|c|}
\hline No. & Scene & Location & Duration & $\begin{array}{l}\text { INT/ } \\
\text { EXT }\end{array}$ & Description \\
\hline 1. & 5 & $\begin{array}{l}\text { Halaman } \\
\text { rumah }\end{array}$ & $\begin{array}{l}00: 01: 51- \\
00: 01: 57\end{array}$ & INT & $\begin{array}{l}\text { Menampilkan lower } \\
\text { third Tiodor }\end{array}$ \\
\hline 2. & 6 & $\begin{array}{l}\text { Halaman } \\
\text { rumah }\end{array}$ & $\begin{array}{c}00: 02: 15- \\
00: 02: 20\end{array}$ & INT & $\begin{array}{l}\text { Menampilkan lower } \\
\text { third TopGrow }\end{array}$ \\
\hline 3. & 2 & $\begin{array}{l}\text { Tanaman } \\
\text { hias }\end{array}$ & $\begin{array}{l}\text { 00:00:02 - } \\
\text { 00:00:05 }\end{array}$ & $E X T$ & $\begin{array}{l}\text { Menampilkan footage } \\
\text { tanaman dan logo PT. } \\
\text { CBA Mitra }\end{array}$ \\
\hline 4. & 3 & $\begin{array}{l}\text { Lahan } \\
\text { Tanaman }\end{array}$ & $\begin{array}{c}\text { 00:00:06 - } \\
\text { 00:00:07 }\end{array}$ & $E X T$ & $\begin{array}{l}\text { Menampilkan footage } \\
\text { lahan tanaman bunga }\end{array}$ \\
\hline 5. & 4 & Daun & $\begin{array}{c}00: 00: 48- \\
00: 00: 51\end{array}$ & $E X T$ & $\begin{array}{l}\text { Menampilkan text } \\
\text { hama yang sering } \\
\text { menyerang tanaman } \\
\text { hias dan bibit buah }\end{array}$ \\
\hline 6. & 7 & $\begin{array}{l}\text { Lahan } \\
\text { Tanaman }\end{array}$ & $\begin{array}{c}00: 04: 19- \\
00: 04: 42\end{array}$ & $E X T$ & $\begin{array}{l}\text { Menampilkan video } \\
\text { penyemprotan } \\
\text { tanaman hias }\end{array}$ \\
\hline 7. & 8 & $\begin{array}{c}\text { Area } \\
\text { Tanaman }\end{array}$ & $\begin{array}{c}00: 04: 43- \\
00: 05: 23\end{array}$ & $E X T$ & $\begin{array}{l}\text { Menampilkan video } \\
\text { penyuluhan terhadap } \\
\text { petani atau masyarakat }\end{array}$ \\
\hline
\end{tabular}




\section{Penyusunan Crew}

Untuk dapat terealisasikannya video penyuluhan ini, dibentuknya susunan crew yang terlibat yaitu : sutradara, cameraman, drone pilot, editor, script writer, voice over. Berikut ini adalah jobdesk dan nama-nama yang diikut sertakan dalam pembuatan video penyuluhan hama tanaman PT.CBA Mitra :

Tabel 3. Urutan Crew

\begin{tabular}{|c|c|c|}
\hline No. & Jabatan & Nama \\
\hline 1. & Director & Adam Wiradi Arif \\
\hline 2. & Cameraman & Alam Putra Prasetyo \\
\hline 3. & Drone Pilot & Adam Wiradi Arif \\
\hline 4. & Editor & Alam Putra Prasetyo \\
\hline 5. & Script Writer & Alam Putra Prasetyo \\
\hline 6. & Voice Over & Reva Putri \\
\hline
\end{tabular}

\section{Time schedule}

Time Schedule adalah perancangan waktu ketika produksi berlangsung. Berikut time schedule video penyuluhan hama tanaman PT.CBA Mitra :

Tabel 4. Time Schedule

\begin{tabular}{|c|c|c|c|c|c|c|c|c|c|c|c|c|c|c|c|c|c|}
\hline \multirow{2}{*}{\multicolumn{2}{|c|}{ Tahapan }} & \multicolumn{4}{|c|}{$\begin{array}{c}\text { Oktober } \\
2020\end{array}$} & \multicolumn{4}{|c|}{$\begin{array}{c}\text { Novembe } \\
\text { r } \\
2020\end{array}$} & \multicolumn{4}{|c|}{$\begin{array}{c}\text { Desember } \\
2020\end{array}$} & \multicolumn{4}{|c|}{$\begin{array}{c}\text { Januari } \\
2021\end{array}$} \\
\hline & & 1 & 2 & 3 & 4 & 1 & 2 & 3 & 4 & 1 & 2 & 3 & 4 & 1 & 2 & & 4 \\
\hline \multirow{3}{*}{$\begin{array}{l}P \\
r \\
e\end{array}$} & $\begin{array}{l}\text { Pengajuan } \\
\text { Observasi }\end{array}$ & & & & & & & & & & & & & & & & \\
\hline & $\begin{array}{l}\text { Pengumpulan } \\
\text { Data }\end{array}$ & & & & & & & & & & & & & & & & \\
\hline & Analisis Data & & & & & & & & & & & & & & & & \\
\hline \multirow{2}{*}{$\begin{array}{c}p \\
r\end{array}$} & Ide/Gagasan & & & & & & & & & & & & & & & & \\
\hline & Sinopsis/Cerita & & & & & & & & & & & & & & & & \\
\hline \multirow{2}{*}{$\begin{array}{l}o \\
d \\
u\end{array}$} & Narasi & & & & & & & & & & & & & & & & \\
\hline & $\begin{array}{l}\text { Pembuatan } \\
\text { Storyboard }\end{array}$ & & & & & & & & & & & & & & & & \\
\hline \multirow{2}{*}{$\begin{array}{l}c \\
t\end{array}$} & Script Writing & & & & & & & & & & & & & & & & \\
\hline & Rundown & & & & & & & & & & & & & & & & \\
\hline \multirow{2}{*}{$\begin{array}{l}i \\
o\end{array}$} & Penyusunan $\mathrm{Crew}$ & & & & & & & & & & & & & & & & \\
\hline & Time Schedule & & & & & & & & & & & & & & & & \\
\hline \multirow[t]{2}{*}{$n$} & Anggaran/Budget & & & & & & & & & & & & & & & & \\
\hline & $\begin{array}{l}\text { Peralatan Yang } \\
\text { Digunakan }\end{array}$ & & & & & & & & & & & & & & & & \\
\hline \multirow{3}{*}{$\begin{array}{l}o \\
d \\
u \\
c\end{array}$} & $\begin{array}{l}\text { Perencanaan } \\
\text { Multimedia }\end{array}$ & & & & & & & & & & & & & & & & \\
\hline & $\begin{array}{l}\text { Perencanaan } \\
\text { Audio }\end{array}$ & & & & & & & & & & & & & & & & \\
\hline & $\begin{array}{l}\text { Perencanaan } \\
\text { Visual }\end{array}$ & & & & & & & & & & & & & & & & \\
\hline
\end{tabular}


Print ISSN: 2723-1992

Online ISSN: 2723-200X

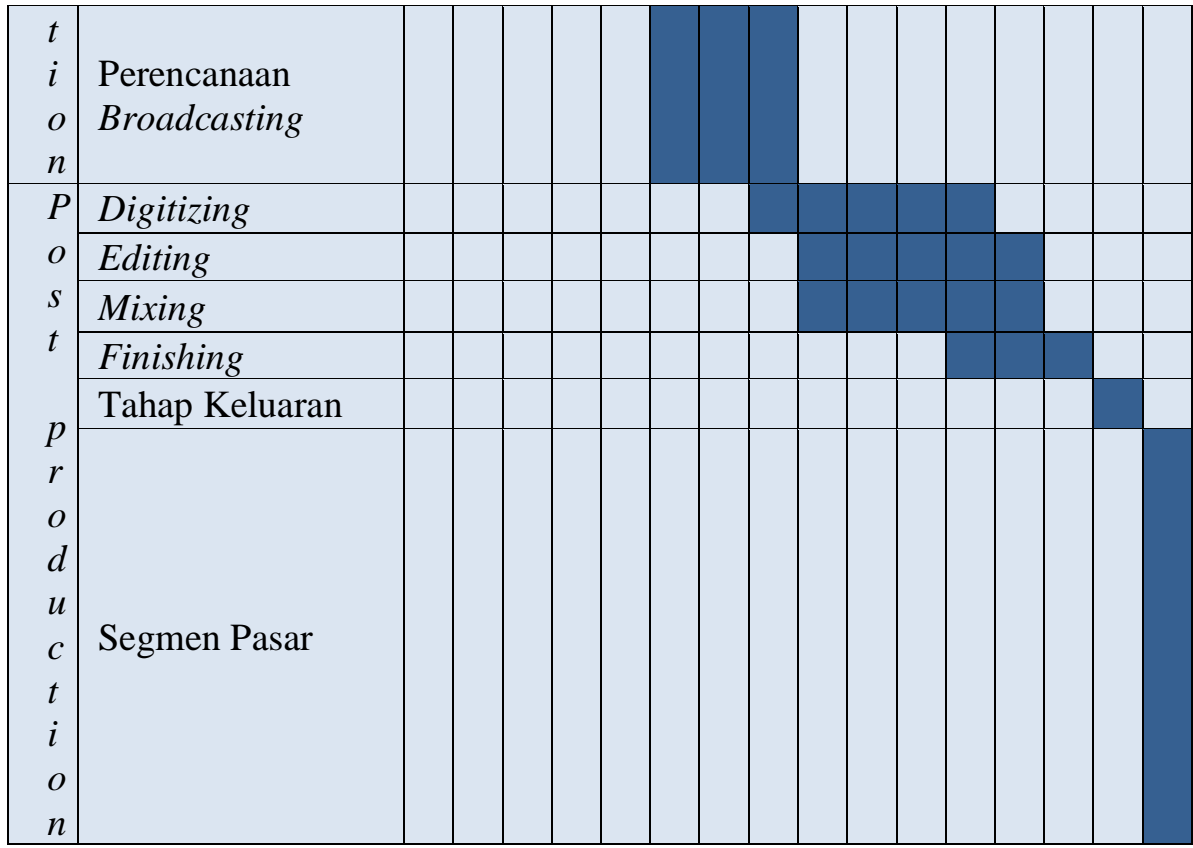

9. Peralatan yang digunakan

Adapun kelengkapan yang berperan aktif saat produksi berjalan yakni Camera Mirroless Sony A7 Mark II, Camera Mirroless Sony A5000, Dji Spark Quadcopter Drone, Lensa Sony 16-35mm, Zhiyun Stabilizher, Lighting LED, Clip On Boya, Memory Sandisk Ultra 32GB, DVD dan Laptop.

\subsection{Production}

Production adalah suatu kegiatan kolaborasi antar crew untuk saling melengkapi dalam pembuatan video guna memenuhi kebutuhan shooting.

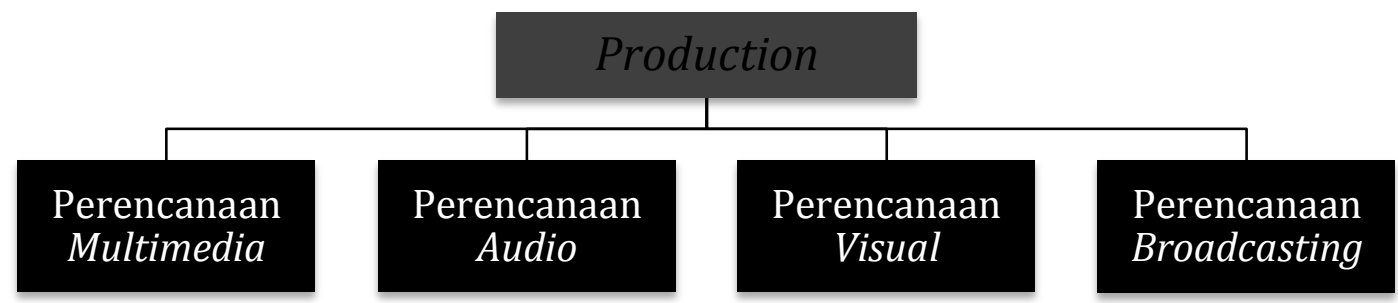

Program Visual

Gambar 12. Production

Program visual terdiri dari beberapa software yang diterapkan seperti Adobe Premiere Pro CC 2019, Adobe After Effect 2019 dan Adobe Photoshop Pro CC 2019. 
Print ISSN: 2723-1992

Online ISSN: 2723-200X

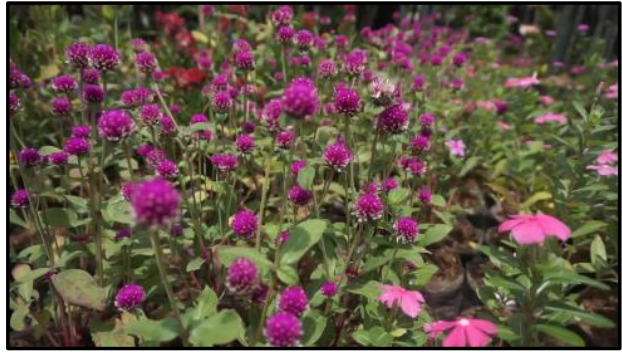

Gambar 13. Scene 1/Video Opening

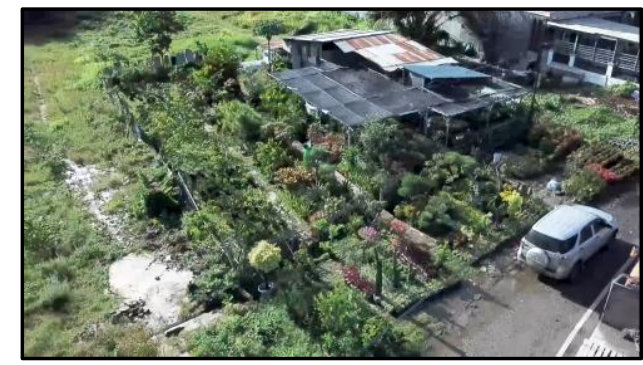

Gambar 15. Scene 3/Day/Long Shot/Footage Lahan tanaman bunga

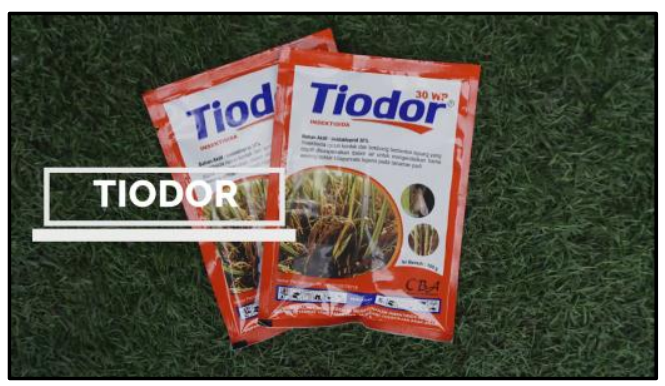

Gambar 17. Scene 5/Day/High Shot/Lower third Tiodor

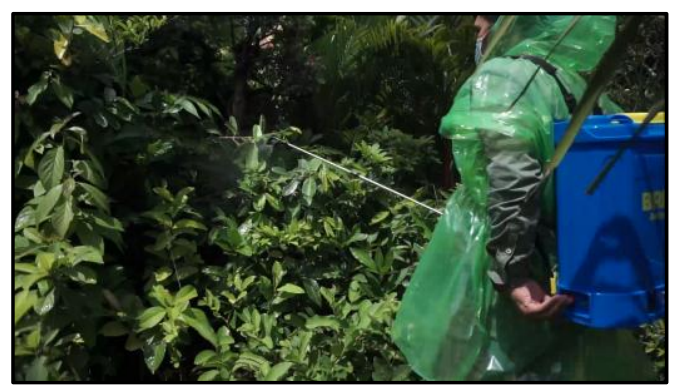

Gambar 19. Scene 7/Day/Close Up/Viderado penyemprotan tanaman hias

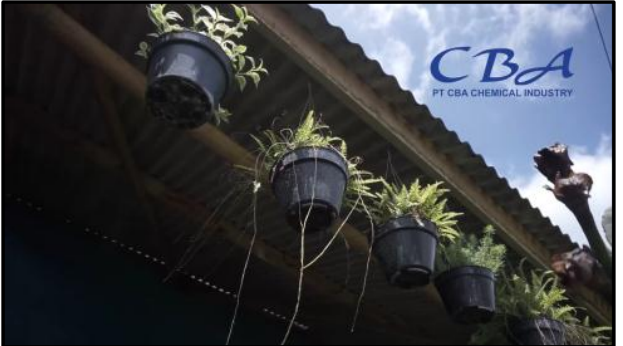

Gambar 14. Scene 2/Day/Low Shot/footage tanaman dan logo PT. CBA Mitra

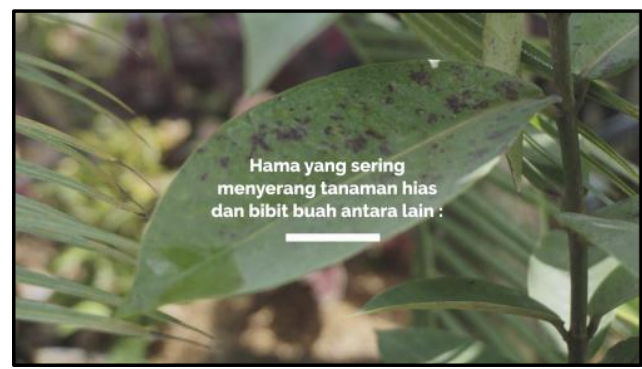

Gambar 16. Scene 4/Medium Shot/Text hama yang sering menyerang tanaman hias dan bibit buah

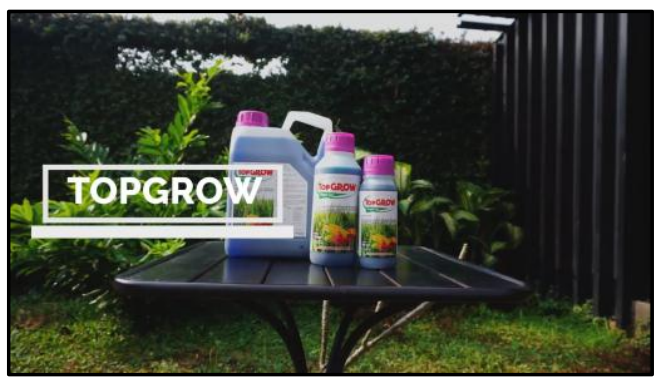

Gambar 18. Scene 6/Day/Long Shot/Lower third TopGrow

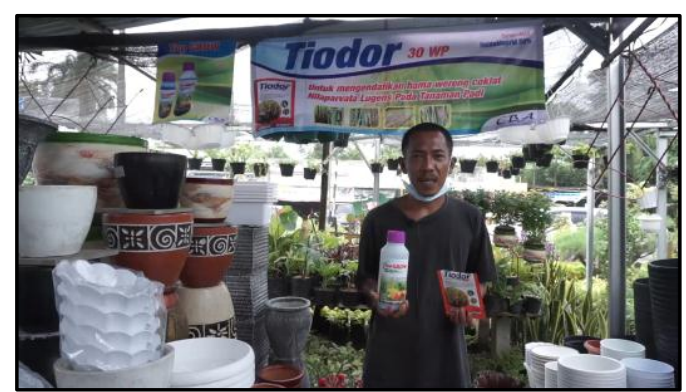

Gambar 20. Scene 8/day/ Medium

Fullshot/Video closing program acara siaran 

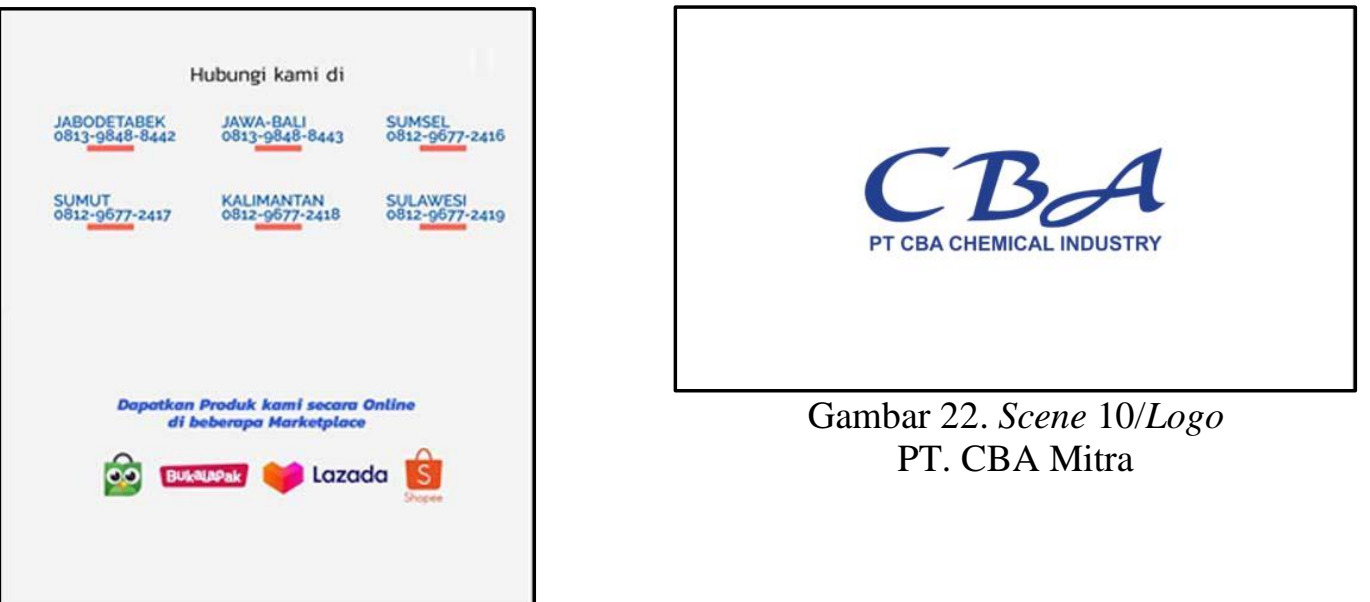

Gambar 21. Scene 9/Video nomor telephone, marketplace

\subsection{Post Production}

Pada tahap ini meliputi proses digitizing, editing, mixing, finishing, exporting dan segmen pasar.

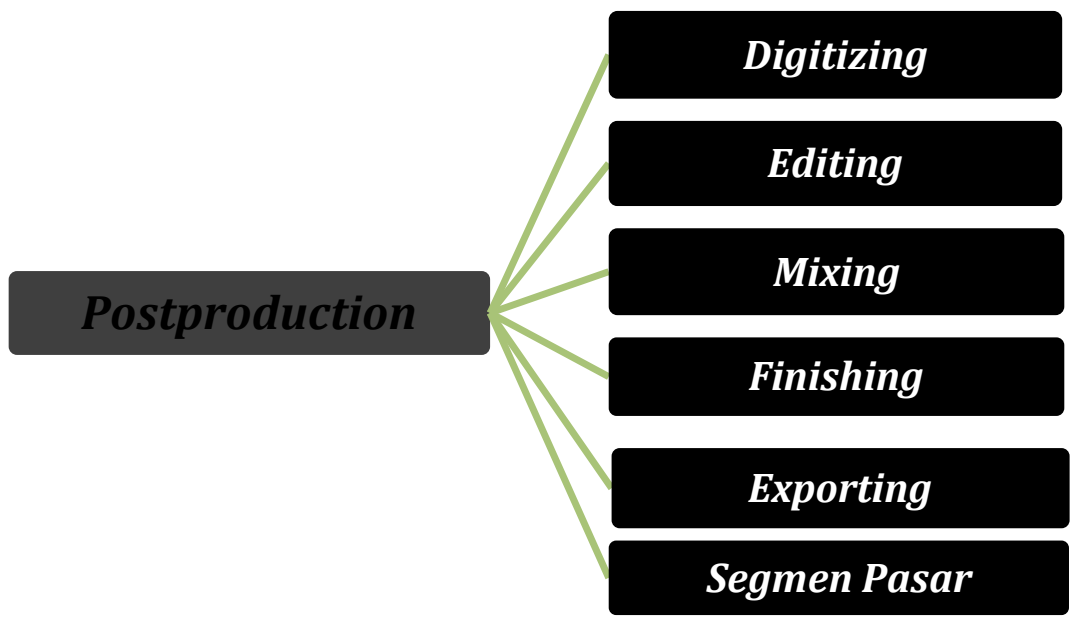

Gambar 23. Post Production

1. Digitizing

Proses ini ialah penyalinan gambar menjadi bentuk file dinary dan mengkajinya dari hasil shooting untuk dilanjutkan ke tahap editing.

2. Editing

Pada tahap ini membentuk sebuah proses memotong dan menyambungkan beberapa video terpilih sesuai dengan konsep yang telah ditentukan.

3. Mixing

Mixing adalah tahap pengolahan antara video, sound dan effect, ditahap ini Software yang digunakan yaitu Adobe Premiere Pro CC 2019, Adobe Audition CC 2019 dan Adobe Photoshop Pro CC 2019. 


\section{Finishing}

Finishing ialah tahap penyempurnaan dari video editing penyuluhan ini, di tahap ini harus teliti untuk menyatukan visualiasi supaya video terlihat menarik.

\section{Exporting}

Proses ini merupakan tujuan akhir dari semua tahapan yang telah dilakukan dalam pembuatan video penyuluhan ini, setelah semua terpenuhi exporting akan dilakukan menggunakan software Adobe Premiere Pro CC 2019, dengan memastikan kualitas video terbaik. Kemudian hasil render ini akan di unggah ke dalam Youtube "PT. CBA Mitra".

6. Segmen Pasar

Segmen pasar bertujuan untuk menjangkau luasnya target pemasaran melalui video ini dan diharapkan dapat lebih menarik minat konsumen dan pertani

\section{KESIMPULAN}

Berdasarkan hasil kesimpulan penelitian mengenai Pengembangan Video PT. CBA Mitra oleh PT. Anugrah Creative Media yaitu sebagai berikut :

Strategi pemasaran yang dilakukan PT. Anugrah Creative Media dalam memberikan informasi dan promosi produk PT. CBA Mitra dengan implementasi media video penyuluhan melalui youtube channel PT. Anugrah Creative Media dan juga menayangkan video penyuluhan ini secara langsung pada saat presentasi klien yang diselenggarakan oleh PT. CBA Mitra dan PT. Anugrah Creative Media.

Dalam menyiapkan sebuah media video penyuluhan nan mengagumkan dan bermanfaat bagi audience yaitu dengan konsep video penyuluhan dengan ide cerita yang menarik, informatif, serta didukung dengan audio, dubbing, visualisasi dengan tampilan video berkualitas $H D$, disertai berbagai effect visualisasi aktif, mampu menjadikan suatu ketertaikan bagi penonton.

Tujuan informasi dari PT. Anugerah Creative Media melalui video penyuluhan PT. CBA Mitra ini yaitu mengenai keseluruhan ruang lingkup profil, proses pembuatan produk hama tanaman dan filosofi PT. CBA Mitra.

\section{SARAN}

Berlandaskan hasil kesimpulan dari penilitian ini, termuat sejumlah saran yang diperkenankan, diantaranya :

Disarankan kepada PT. Anugrah Creative Media, agar dapat memperluas sebaran informasi dan promosi PT. CBA Mitra ini, agar melalui video penyuluhan ini produk PT. CBA Mitra dapat lebih dikenal bukan hanya di Indonesia tetapi juga dikenal Mancanegara.

Disarankan kepada PT. Anugerah Creative Media agar selalu mengembangkan ide-ide dengan konsep video yang lebih inovatif, kreatif, fresh, serta lebih menarik kedepannya seperti tampilan video yang didukung dengan animasi interaktif sehingga dapat lebih menarik minat klien untuk bekerjasama dengan PT. Anugerah Creative Media dalam menghasilkan karya audio visual.

Disarankan kepada PT. Anugerah Creative Media agar selalu menampilkan informasiinformasi terbaru sesuai kebutuhan dan keinginan klien PT. CBA Mitra sehingga masyarakat mendapatkan informasi yang update dan dapat memahami informasi yang disampaikan.

\section{DAFTAR PUSTAKA}

[1] Mandacana, Yaer Karenius, Detia Tri Yunandar dan Susanti Indriya Wati. 2020. Penyuluhan Pembuatan dan Pemanfaatan Pupuk Organik Cair diKelompok Tani Sougp Hatam 1 Kampung Lismaunggu Distrik Prafi, Kabupaten Manokwari Provinsi Papua 
Barat. Manokwari: Politeknik Pembangunan Pertanian Manokwari. Prosiding Seminar Nasional Pembangunan dan Pendidikan Vokasi Pertanian. ISSN: 27741982. Vol.1, No.1: 256.

[2] Valentino, Dion Eko dan Muhammad Jodi Hardiansyah. 2020. Perancangan Video Company Profile Pada Hotel de Java Bandung. Bandung : Politeknik LP3I Bandung. Jurnal TEMATIK. ISSN: 2355-9055. Vol.7, No.1 : 2.

[3] Mawan, Agni Rimba. Sri Endah Indriwati dan Suhadi. 2017. Pengembangan Video Penyuluhan Perilaku Hidup Bersih Dan Sehat (Phbs) Bermuatan Nilai Karakter Terhadap Peningkatan Pengetahuan Masyarakat Dalam Menanggulangi Penyakit Diare. Malang : Universitas Negeri Malang. Jurnal Pendidikan. ISSN : 2502-471X. Vol.2, No.7 : 884 .

[4] Acuña-Soto, Claudia Margarita. Vicente Liern and Blanca Pérez-Gladish. 2018. Multiple criteria performance evaluation of YouTube mathematical educational videos by IS-TOPSIS. Operational Research an International Journal. Vol.18, Issue. 1 : 3.

[5] Safitri, Eza. Ernita Arif dan Asmawi. 2020. Penggunaan Media Sosial Dalam Penyuluhan Pertanian Di Kecamatan Tiumang Kabupaten Dharmasraya. Padang : Universitas Andalas. Jurnal Niara. ISSN : 1693-3516. Vol.13, No.2 : 93.

[6] Putri, Rizky Trisna dan Reza Safitri. 2018. Peran Penyuluh Pertanian Terhadap Penerapan Teknologi Tanam Jajar Legowo 2:1 (Kasus Kelompok Tani Gotong Royong 2 Di Desa Klaseman, Kabupaten Probolinggo). Malang : Universitas Brawijaya. Jurnal Ekonomi Pertanian dan Agribisnis (JEPA). ISSN : 2614-4670. Vol.2, No.3 : 170.

[7] Salaki, Christina L. dan Jantje Pelealu. 2019. Pengendalian Hama Tanaman Padi Berbasis Ramah Lingkungan. Manado : Universitas Sam Ratulangi. Techno Science Journal. ISSN : 2715-8322. Vol.1, No.1 : 25. 